\title{
Rekomendasi Laptop Gaming High end untuk Gamer Professional dengan Elimination Et Choix Traduisant la Realite (ELECTRE)
}

\author{
Ester Arisawati ${ }^{1}$, Rinawati ${ }^{2}$, Frisma Handayanna ${ }^{3}$, Erene Gernaria Sihombing ${ }^{4}$, Linda \\ Sari Dewi ${ }^{5}$ \\ 1,2,3,4,5STMIK Nusa Mandiri \\ Jl. Kramat Raya No.18 Jakarta Pusat \\ erene.egs@nusamandiri.ac.id
}

\begin{abstract}
The purpose of this research is as a recommendation tool in determining high end gaming laptops for professional gamers by using a decision support system. The settlement method used in this study is Elimination Et Choix Traduisant la Realite (ELECTRE). The data collection techniques were carried out randomly by conducting observations, interviews and questionnaires to 250 respondents (gamers) and 10 computer shops in the district of Simalungun. In this study, using five alternatives, among others: Asus ROG G703 (A1), Razer Blade Pro (A2) MSI GT75VR Titan083 (A3), Acer Predator Triton 700 (A4), Alienware 17 (A5) and five assessment criteria, among others: Price (C1), Processor Type (C2), RAM Capacity (C3), VGA Card Type (C4) and Hard Drive (C5). The results of the Elimination Et Choix Traduisant la Realite (ELECTRE) method recommend the Predator Triton 700 (A4) alternative as the first recommendation for the selection of high end gaming laptops for professional gamers.
\end{abstract}

Keywords: Decision Support System, ELECTRE, Laptop Gaming, Professional

\begin{abstract}
Abstrak
Tujuan dari penelitian ini adalah sebagai alat rekomendasi dalam menentukan laptop gaming high end untuk gamer professional dengan menggunakan sistem pendukung keputusan. Metode penyelesaian yang digunakan pada penelitian ini adalah Elimination Et Choix Traduisant la Realite (ELECTRE). Adapun teknik pengumpulan data dilakukan secara acak dengan melakukan observasi, wawancara dan angket ke 250 responden (gamer) dan 10 toko komputer di wilayah kabupaten simalungun. Pada penelitian ini menggunakan lima alternatif antara lain: Asus ROG G703 (A1), Razer Blade Pro (A2) MSI GT75VRTitan-083 (A3), Acer Predator Triton 700 (A4), Alienware 17(A5) dan lima kriteria penilaian antara lain: Harga (C1), Jenis Processor (C2), Kapasitas RAM (C3), Jenis Kartu VGA (C4) dan Hardisk (C5). Hasil dari perhitungan metode Elimination Et Choix Traduisant la Realite (ELECTRE) merekomendasikan alternatif Predator Triton 700 (A4) sebagai rekomendasi pertama untuk pemilihan laptop gaming high end untuk gamer professional.
\end{abstract}

Kata kunci: Sistem Pendukung Keputusan, ELECTRE, Laptop Gaming, Profesional

\section{PENDAHULUAN}

Saat ini keberadaan laptop tidak lagi di anggap sebagai hal yang mewah. Laptop sudah dijadikan sebagai gaya hidup terutama bagi mereka yang selalu mengikuti perkembangan teknologi. Gamer merupakan satu contoh dari sekian banyak golongan yang selalu mengikuti perkembangan teknologi [1]. Dengan perkembangan games yang semakin cepat, muncul cabang olah raga baru yang disebut eSports yang dikhusukan untuk kompetisi video game. Dari munculnya cabang olah raga baru yang beken ini, muncullah sebutan baru untuk para atlit yang bergelut di dunia ini dan kerap dijuluki Professional Gamer. Namun tidak mudah untuk menjadi seorang gamer 
professional dibutuhkan kemampuan yang selalu di asah dan media yang canggih untuk mendukung pengasahan kemampuannya antara lain laptop gaming high end. Disebut high end berarti laptop tersebut sudah memiliki spesifikasi tinggi diatas rata-rata laptop biasa yang dibutuhkan oleh gamer profesional. Dengan komponen - komponen berspesifikasi tinggi ini dapat menciptakan pengalaman bermain game secara portable. Komunitas tersebut semakin berkembang mengingat kemajuan teknologi sudah mencapai revolusi industri 4.0. Penelitian ini bertujuan untuk merekomendasikan laptop gaming high end yang ideal untuk Gamer Professional, mengingat setiap produk yang ditawarkan memiliki kemampuan masing-masing. Penelitian ini menggunakan sumber data melalui observasi, wawancara dan penyebaran angket ke 250 responden (gamer) dan 10 toko komputer di wilayah kabupaten simalungun. Hasil akhir dari penelitian adalah perangkingan.

Dalam cabang ilmu komputer, ada beberapa cabang ilmu yang menggunakan luaran perangkingan. Salah satunya adalah Sistem Pendukung Keputusan [2][3]-[9]. Penulis menggunakan metode Elimination Et Choix Traduisant la Realite (ELECTRE) karena memiliki beberapa kelebihan yakni menggunakan konsep outranking dengan menggunakan perbandingan berpasangan [10]-[12] dan digunkan pada kasus dengan banyak alternatif namun hanya sedikit kriteria yang dilibatkan [13][15]. Hal tersebut juga dikaitkan dengan penelitian terdahulu yang menggunakan ELECTRE dalam penyelesaian masalah. Seperti yang dilakukan [16] dengan judul penelitian Implementation of Elimination and Choice Expressing Reality (ELECTRE) Method in Selecting the Best Lecturer (Case Study STMIK BUDI DARMA). Pada penelitian ini metode ELECTRE dapat diterapkan dalam penyelesaian pengukuran indeks kinerja dosen di suatu perguruan tinggi sehingga menjadi solusi tepat untuk masalah yang dihadapi oleh pimpinan universitas sebagai pengambil keputusan. Berdasarkan hal tersebut peneliti menggunakan metode ELECTRE untuk merekomendasikan laptop gaming high end yang ideal untuk Gamer Professional yang nantinya hasil perhitungan metode ELECTRE dapat dijadikan referensi dalam membeli dan menggunakan laptop gaming.

\section{METODOLOGI PENELITIAN}

\subsection{Elimination Et Choix Traduisant la Realite (ELECTRE)}

ELECTRE merupakan salah satu metode pengambilan keputusan multikriteria berdasarkan pada konsep Outranking yang digunakan pada kondisi dimana alternatif yang kurang sesuai dengan kriteria dieliminasi, dan alternatif yang sesuai dapat dihasilkan [17], [18]. Adapun Langkah-langkah yang dilakukan dalam penyelesaian ELECTRE sebagai berikut :

a. Normalisasi matriks keputusan

Dalam prosedur ini, setiap atribut diubah menjadi nilai yang compareable. Setiap normalisasi $\mathrm{r}_{\mathrm{ij}}$ dapat dilakukan dengan persamaan (1):

$$
r_{i j}=\frac{x_{i j}}{\sqrt{\sum_{i=1}^{m} x_{i j}{ }^{2}}}
$$


Keterangan :

$r_{i j}=$ normalisasi pengukuran pilihan darialternatif dan kriteria.

$m=$ Alternatif.

$n=$ Kriteria.

Sehingga di dapat matriks $R$ ternormalisasi, seperti dibawah ini.

$$
r_{i j=}\left[\begin{array}{lllll}
r_{11} & r_{12} & r_{13} & \ldots & r_{1 n} \\
r_{21} & r_{22} & r_{23} & \ldots & r_{2 n} \\
. & . & . & \ldots & . \\
r_{m 1} & r_{m 2} & r_{m 3} & \ldots & r_{m n}
\end{array}\right]
$$

$R$ adalah matriks yang telah dinormalisasi atau disebut normalized decision matrix. Dimana $m$ menyatakan alternatif, $n$ menyatakan criteria dan rij adalah normalisasi pengukuran pilihan dari alternatif ke- $i$ dalam hubungannya dengan kriteria ke-j.

\section{b. Pembobotan pada matriks yang telah dinormalisasi.}

Setelah dinormalisasi, setiap kolom darimatriks $R$ dikalikan dengan bobot-bobot $\left(w_{j}\right)$ yang ditentukan oleh pembuat keputusan. Sehingga, wighted normalized matrix adalah $V=R W$ adalah yang ditulis persamaan (2).

$$
V=\left[\begin{array}{cccc}
v_{11} & v_{12} & \cdots & v_{1 n} \\
v_{21} & v_{22} & \cdots & v_{2 n} \\
\vdots & & & \\
v_{m 1} & v_{m 2} & \cdots & v_{m n}
\end{array}\right] R W=\left[\begin{array}{cccc}
w_{1} r_{11} & w_{1} r_{12} & \cdots & w_{n} r_{1 n} \\
w_{1} r_{21} & w_{2} r_{22} & \cdots & w_{n} r_{2 n} \\
\vdots & & \\
w_{1} r_{m 1} & w_{2} r_{m 2} & \cdots w_{n} r_{m n}
\end{array}\right]
$$

Dimana $W$ adalah :

$$
W=\left[\begin{array}{cccc}
w_{1} & 0 & \cdots & 0 \\
v_{21} & w_{2} & \cdots & 0 \\
\vdots & & & \\
0 & 0 & \cdots & w_{n}
\end{array}\right]
$$

$\sum_{j=1}^{n} W_{j}=1$

\section{c. Menentukan concordance dan discordance index}

Untuk setiap pasang dari alternatif $k$ dan $l(k, l \quad 1,2,3, \ldots,=m$ dan $k \quad 1 \neq$ ) kumpulan kriteria Jdibagi menjadi dua subsets, yaitu concordance dan discordance. Bilamana sebuah kriteria dalam satu alternatif termasuk concordance

$$
C_{k l}=\left\{j \mid V_{k j} \geq V_{l j}\right\} \text { dengan } \mathrm{j}=1,2, \ldots, \mathrm{n}
$$

Sebaliknya, komplementer dari subset ini adalah discordance, yaitu bila:

$$
D_{k l}=\left\{j \mid V_{k j}<V_{l j}\right\} \quad \text { dengan } \mathrm{j}=1,2, \ldots, \mathrm{n}
$$


Keterangan :

$C_{k l}=$ himpunan concordance

$D_{k l}=$ himpunan discordance .

$V_{k j}=$ indeks dari matriks $\mathrm{V}$.

$V_{i j}=$ indeks dari matriks $\mathrm{V}$.

d. Hitung matriks concordance dan discordance

1) Concordance

Untuk menentukan nilai dari elemen-elemen pada matriks concordance adalah dengan menjumlahkan bobot-bobot yang termasuk dalam subset concordance, secara matematisnya(5):

$C_{k l}=\sum_{j \in C_{k l}} W_{j}$

Sehingga matriks concordance yang dihasilkan adalah:

$$
C_{i j=}\left[\begin{array}{llll} 
& C_{12} & \ldots & C_{1 n} \\
C_{21} & - & \ldots & C_{2 n} \\
\cdot & \cdot & - & \cdot \\
C_{m 1} & C_{m 2} & \ldots & -
\end{array}\right]
$$

\section{2) Discordance}

Untuk menentukan nilai dari elemen-elemen pada matriks discordance adalah dengan membagi maksimum selisih nilai kriteria yang termasuk dalam subset discordance dengan maksimum selisih nilai seluruh kriteria yang ada:

$D_{k l}=\frac{\max \left\{\left|V_{k j}-V_{l j}\right|\right\} \quad j \in D_{k l}}{\max \left\{\left|V_{k j}-V_{l j}\right|\right\} \quad V_{j}}$

Selanjutnya diperoleh matriks discordance :

$$
d_{i j=}\left[\begin{array}{llll} 
& d_{12} & \ldots & d_{1 n} \\
d_{21} & - & \ldots & d_{2 n} \\
\cdot & \cdot & - & \cdot \\
d_{m 1} & d_{m 2} & \ldots & -
\end{array}\right]
$$

e. Menentukan matriks dominan concordance dan discordance

1) Concordance

Matriks dominan concordance dapat dibangun dengan bantuan nilai threshold, yaitu dengan membandingkan setiap nilai elemen matriks concordance dengan nilai threshold. 
$C k l \geq c$

Dengan nilai threshold (ㄷ) ), adalah :

$\underline{c}=\frac{\sum_{k=1}^{m} \sum_{l=1}^{m} C_{k l}}{m(m-1)}$

Dan setiap elemen matriks $F$ sebagai matriks dominan concordance ditentukan sebagai berikut :

$f_{k l}=\left\{\frac{1, j i k a C_{k l} \geq \underline{C}}{0, j i k a C_{k l}<\underline{C}}\right.$

2) Discordance

Untuk membangun matriks dominan discordance juga menggunakan bantuan nilai threshold, yaitu :

$\underline{d}=\frac{\sum_{k=1}^{m} \sum_{l=1}^{m} D_{k l}}{m(m-1)}$

Dan nilai setiap elemen untuk matriks $G$ sebagai matriks dominan discordance ditentukan sebagai berikut :

$g_{k l}=\left\{\frac{1, j i k a D_{k l}<\underline{D}}{0, j i k a D_{k l} \geq \underline{D}}\right.$

\section{f. Menentukan aggregate dominance matrix}

Langkah selanjutnya adalah menentukan aggregate dominance matrix sebagai matriks $E$, yang setiap elemennya merupakan perkalian antara elemen matriks $F$ dengan elemen matriks $G$, sebagai berikut :

$e_{k l}=f_{k l} * g_{k l}$

g. Eliminasi alternatifyang less favourable

Matriks $E$ memberikan urutan pilihan darisetiap alternatif, yaitu bila $e k l$ 1= maka alternatif $A k$ merupakan pilihan yang lebih baik daripada $A_{r}$ sehingga baris dalam matriks $E$ yang memiliki jumlah $e_{k l}=1$ paling sedikit dapat dieliminasi. Dengan demikian alternatif terbaik adalah yang mendominasi alternatif lainnya.

\section{HASIL DAN PEMBAHASAN}

\subsection{Proses Data Masukan}

Berikut data masukan dari alternatif pada pemilihan laptop gaming high end yang ideal untuk Gamer Professional seperti yang ditunjukkan pada tabel berikut: 
Tabel 1. Proses Data Masukan

\begin{tabular}{|c|c|c|c|c|c|}
\hline \multirow{2}{*}{ Alternatif } & \multicolumn{5}{|c|}{ Kriteria } \\
\cline { 2 - 6 } & Harga & Jenis Processor & $\begin{array}{c}\text { Kapasitas } \\
\text { RAM }\end{array}$ & Jenis Kartu VGA & Hardisk \\
\hline Asus ROG G703 & 62.988 .000 & $\begin{array}{c}\text { Intel Core i7 - } \\
7820 \mathrm{HK}\end{array}$ & $32 \mathrm{~GB}$ & $\begin{array}{c}\text { Nvidia GeForce } \\
\text { GTX 1080 }\end{array}$ & $1 \mathrm{~TB}$ \\
\hline Razer Blade Pro & 52.800 .000 & $\begin{array}{c}\text { Intel Core i7 - } \\
6700 \mathrm{HQ}\end{array}$ & $32 \mathrm{~GB}$ & $\begin{array}{c}\text { Nvidia GeForce } \\
\text { GTX 1080 }\end{array}$ & $2 \mathrm{~TB}$ \\
\hline $\begin{array}{c}\text { MSI GT75VR } \\
\text { Titan-083 }\end{array}$ & 69.482 .000 & $\begin{array}{c}\text { Intel Core i7- } \\
7820 \mathrm{HK}\end{array}$ & $64 \mathrm{~GB}$ & $\begin{array}{c}\text { Nvidia GeForce } \\
\text { GTX 1070 }\end{array}$ & $1 \mathrm{~TB}$ \\
\hline $\begin{array}{c}\text { Acer Predator } \\
\text { Triton 700 }\end{array}$ & 56.250 .000 & $\begin{array}{c}\text { Intel Core i7- } \\
7700 \mathrm{HQ}\end{array}$ & $16 \mathrm{~GB}$ & $\begin{array}{c}\text { Nvidia GeForce } \\
\text { GTX 1080 }\end{array}$ & $1 \mathrm{~TB}$ \\
\hline Alienware 17 & 32.000 .000 & $\begin{array}{c}\text { Intel Core i7- } \\
4710 \mathrm{HQ}\end{array}$ & $16 \mathrm{~GB}$ & $\begin{array}{c}\text { Nvidia GeForce } \\
\text { GTX 980 }\end{array}$ & $1 \mathrm{~TB}$ \\
\hline
\end{tabular}

Pada tabel 1 dapat dijelaskan parameter yang digunakan pada data penelitian: A1 : Asus R0G G703, A2 : Razer Blade Pro, A3 : MSI GT75VRTitan-083, A4 : Acer Predator Triton 700, A5 : Alienware 17.

C1 : Harga, C2: Jenis Processor, C3 : Kapasitas Ram, C4 : Jenis Kartu VGA, C5 : Hardisk

\subsection{Praproses}

Tahap praproses pada metode ELECTRE menentukan rating kecocokan pada setiap kriteria. Rating kecocokan ditentukan berdasarkan dari hasil wawancara yang terdiri dari :

\section{a) Harga}

Berikut rating kecocokan yang digunakan untuk kriteria Harga (C1):

\section{b) Jenis Processor}

Tabel 2. Rating Kecocokan Harga

Berikut rating kecocokan yang digunakan untuk kriteria jenis processor (C2):

Tabel 3. Rating Kecocokan Jenis Processor

\begin{tabular}{|l|l|c|}
\hline Nilai Jenis Processor & Bobot & Nilai \\
\hline Intel Core i7 - 4710HQ & Cukup & 2 \\
\hline Intel Core i7 - 7820HK & Baik & 3 \\
\hline Intel Core i7 - 7700HQ & Cukup Baik & 4 \\
\hline Intel Core i7 - 6700HQ & Sangat Baik & 5 \\
\hline
\end{tabular}




\section{c) Kapasitas RAM}

Berikut rating kecocokan yang digunakan untuk kriteria Kapasitas RAM (C3):

Tabel 4. Rating Kecocokan Kapasitas RAM

\begin{tabular}{|l|l|c|}
\hline Nilai RAM & Bobot & Nilai \\
\hline $16 \mathrm{gb}$ & Baik & 3 \\
\hline $32 \mathrm{gb}$ & Cukup Baik & 4 \\
\hline $64 \mathrm{gb}$ & Sangat Baik & 5 \\
\hline
\end{tabular}

\section{d) Jenis Kartu VGA}

Berikut rating kecocokan yang digunakan untuk kriteria jenis kartu VGA (C4):

Tabel 5. Rating Kecocokan Jenis Kartu Vga

\begin{tabular}{|l|l|r|}
\hline Nilai VGA & Bobot & Nilai \\
\hline Nvidia GeForce GTX 980 & Baik & 3 \\
\hline Nvidia GeForce GTX 1070 & Cukup Baik & 4 \\
\hline Nvidia GeForce GTX 1080 & Sangat Baik & 5 \\
\hline
\end{tabular}

\section{e) Hardisk}

Berikut rating kecocokan yang digunakan untuk kriteria hardisk (C5):

Tabel 6. Rating Kecocokan Hardisk

\begin{tabular}{|l|l|c|}
\hline Nilai Hardisk & Bobot & Nilai \\
\hline 1 TB & Cukup Baik & 4 \\
\hline 2 TB & Sangat Baik & 5 \\
\hline
\end{tabular}

Bobot untuk setiap kriteria didapat dari hasil wawancara dengan ketentuan sebagai berikut :

$\mathrm{W}=\{3,5,5,4,3\}$

keterangan bobot $\mathrm{W}$ sebagai berikut :

1. Indeks 1 (W1) diisi dengan angka 3 yang menunjukkan bobot untuk harga.

2. Indeks 2 (W2) diisi dengan angka 5 yang menunjukkan bobot untuk Jenis Processor.

3. Indeks 3 (W3) diisi dengan angka 5 yang menunjukkan bobot untuk Kapasitas Ram.

4. Indeks 4 (W4) diisi dengan angka 4 yang menunjukkan bobot untuk Jenis Kartu VGA.

5. Indeks 5 (W5) diisi dengan angka 3 yang menunjukkan bobot untuk Hardisk.

Berdasarkan rating kecocokan tersebut maka diperoleh hasil konversi tabel seperti yang ditunjukkan pada tabel berikut: 
Tabel 7. Hasil Praproses

\begin{tabular}{|c|c|c|c|c|c|}
\hline \multirow{2}{*}{ Alternativ } & \multicolumn{5}{|c|}{ Kriteria } \\
\cline { 2 - 6 } & C1 & C2 & C3 & C4 & C5 \\
\hline A1 & 3 & 3 & 4 & 5 & 4 \\
\hline A2 & 4 & 5 & 4 & 5 & 5 \\
\hline A3 & 1 & 3 & 5 & 4 & 4 \\
\hline A4 & 1 & 4 & 3 & 5 & 4 \\
\hline A5 & 5 & 2 & 3 & 3 & 4 \\
\hline
\end{tabular}

\subsection{Proses Perhitungan ELECTRE}

Normalisasi matriks keputusan Tahap ini setiap atribut diubah menjadi nilai yang comparable seperti pada Persamaan (1).

$\left|x_{1}\right|=\sqrt{3^{2}+4^{2}+1^{2}+1^{2}+5^{2}}=\sqrt{52}=$ 7,211102551

$R_{11}=\frac{X_{11}}{X_{1}}=\frac{3}{7,211102551}=0,4160$

$R_{12}=\frac{X_{12}}{X_{1}}=\frac{4}{7,211102551}=0,5547$

$R_{13}=\frac{X_{13}}{X_{1}}=\frac{1}{7,211102551}=0,1387$

$R_{14}=\frac{X_{14}}{X_{1}}=\frac{1}{7,211102551}=0,1387$

$R_{15}=\frac{X_{15}}{X_{1}}=\frac{5}{7,211102551}=0,6934$

$\left|x_{2}\right|=\sqrt{3^{2}+5^{2}+3^{2}+4^{2}+2^{2}}=\sqrt{63}=$ 7,937253933

$R_{21}=\frac{X_{21}}{X_{2}}=\frac{3}{7,937253933}=0,3780$

$R_{22}=\frac{X_{22}}{X_{2}}=\frac{5}{7,937253933}=0,6299$

$R_{23}=\frac{X_{23}}{X_{2}}=\frac{5}{7,937253933}=0,3780$

$R_{24}=\frac{X_{24}}{X_{2}}=\frac{4}{7,937253933}=0,5040$

$R_{25}=\frac{X_{25}}{X_{2}}=\frac{2}{7,937253933}=0,2520$

$\left|x_{3}\right|=\sqrt{4^{2}+4^{2}+5^{2}+3^{2}+3^{2}}=\sqrt{75}=$ 8,660254038

$R_{31}=\frac{X_{31}}{X_{3}}=\frac{4}{8,660254038}=0,4619$

$R_{32}=\frac{X_{32}}{X_{3}}=\frac{4}{8,660254038}=0,4619$
$R_{33}=\frac{X_{33}}{X_{3}}=\frac{5}{8,660254038}=0,5774$

$R_{34}=\frac{X_{34}}{X_{3}}=\frac{3}{8,660254038}=0,3464$

$R_{35}=\frac{X_{35}}{X_{3}}=\frac{3}{8,660254038}=0,3464$

$\left|x_{4}\right|=\sqrt{5^{2}+5^{2}+4^{2}+5^{2}+3^{2}}=\sqrt{100}=10$

$R_{41}=\frac{X_{41}}{X_{4}}=\frac{5}{10}=0,5$

$R_{42}=\frac{X_{42}}{X_{4}}=\frac{5}{10}=0,5$

$R_{43}=\frac{X_{43}}{X_{4}}=\frac{4}{10}=0,5$

$R_{44}=\frac{X_{44}}{X_{4}}=\frac{5}{10}=0,5$

$R_{45}=\frac{X_{45}}{X_{4}}=\frac{3}{10}=0,3$

$\left|x_{4}\right|=\sqrt{4^{2}+5^{2}+4^{2}+4^{2}+4^{2}}=\sqrt{89}=$ 9,433981132

$R_{41}=\frac{X_{41}}{X_{4}}=\frac{4}{9,433981132}=0,4240$

$R_{42}=\frac{X_{42}}{X_{4}}=\frac{5}{9,433981132}=0,5300$

$R_{43}=\frac{X_{43}}{X_{4}}=\frac{4}{9,433981132}=0,4240$

$R_{44}=\frac{X_{44}}{X_{4}}=\frac{4}{9,433981132}=0,4240$

$R_{45}=\frac{X_{45}}{X_{4}}=\frac{4}{9,433981132}=0,4240$

Sehingga didapat matriks $\mathrm{R}$ hasil normalisasi seperti pada Persamaan (2), sebagai berikut: 


$\mathrm{R}=\left[\begin{array}{lllll}0,4160 & 0,3780 & 0,4619 & 0,5 & 0,4240 \\ 0,5547 & 0,6299 & 0,4619 & 0,5 & 0,5300 \\ 0,1387 & 0,3780 & 0,5774 & 0,4 & 0,4240 \\ 0,1387 & 0,5040 & 0,3464 & 0,5 & 0,4240 \\ 0,6933 & 0,2520 & 0,3464 & 0,3 & 0,4240\end{array}\right]$

Pembobotan pada matriks yang telah dinormalisasi. Matriks $\mathrm{V}$ merupakan hasil perkalian $R$ dengan $W$ (bobot), dimana $W=\{\mathbf{3}, \mathbf{5 , 5}, \mathbf{4}, \mathbf{3}\}$. Untuk mencari matriks V dihitung berdasarkan padaPersamaan (3), sebagai berikut :

$\mathrm{V}=\left[\begin{array}{ccccc}1,2480 & 1,8898 & 2,3094 & 2 & 1,2720 \\ 1,6641 & 3,1497 & 2,3094 & 2 & 1,5900 \\ 0,4160 & 1,8898 & 2,8868 & 1,6 & 1,2720 \\ 0,4160 & 2,5197 & 1,7321 & 2 & 1,2720 \\ 2,0801 & 1,2599 & 1,7321 & 1,2 & 1,2720\end{array}\right]$

Kemudian menentukan himpunan concordance dan discordance index. Menentukan himpunan concordance seperti pada Persamaan (3) sehingga diperoleh himpunan concordance pada tabel berikut:

Tabel 8. Himpunan Concordance

\begin{tabular}{|c|c|}
\hline Ckl & Himpunan \\
\hline$C 12$ & $\{3\}$ \\
\hline$C 13$ & $\{1,2,4,5\}$ \\
\hline$C 14$ & $\{1,3,4,5\}$ \\
\hline$C 15$ & $\{2,5\}$ \\
\hline$C 21$ & $\{1,2,3,4,5\}$ \\
\hline$C 23$ & $\{1,2,4,5\}$ \\
\hline$C 24$ & $\{1,2,3,4,5\}$ \\
\hline$C 25$ & $\{2,3,4,5\}$ \\
\hline$C 31$ & $\{2,3,5\}$ \\
\hline$C 32$ & $\{1,2,3,4\}$ \\
\hline$C 34$ & $\{1,3,5\}$ \\
\hline$C 35$ & $\{2,3,4,5\}$ \\
\hline$C 41$ & $\{2,4,5\}$ \\
\hline$C 42$ & $\{4\}$ \\
\hline$C 43$ & $\{1,2,4,5\}$ \\
\hline$C 45$ & $\{2,3,4,5\}$ \\
\hline$C 51$ & $\{1,5\}$ \\
\hline$C 52$ & $\{1\}$ \\
\hline$C 53$ & $\{1,5\}$ \\
\hline$C 54$ & $\{1,3,5\}$ \\
\hline
\end{tabular}

Kemudian menentukan himpunan discordance seperti pada Persamaan (4) sehingga diperoleh himpunan discordance pada tabel berikut :

Tabel 9. Himpunan Discordance

\begin{tabular}{|c|c|}
\hline$D \mathrm{kl}$ & HIMPUNAN \\
\hline$D_{12}$ & $\{1,2,4,5\}$ \\
\hline
\end{tabular}




\begin{tabular}{|c|c|}
\hline$D_{13}$ & $\{3\}$ \\
\hline$D_{14}$ & $\{2\}$ \\
\hline$D_{15}$ & $\{1,3,4\}$ \\
\hline$D_{21}$ & $\{0\}$ \\
\hline$D_{23}$ & $\{3\}$ \\
\hline$D_{24}$ & $\{0\}$ \\
\hline$D_{25}$ & $\{1\}$ \\
\hline$D_{31}$ & $\{1,4\}$ \\
\hline$D_{32}$ & $\{5\}$ \\
\hline$D_{34}$ & $\{2,4\}$ \\
\hline$D_{35}$ & $\{1\}$ \\
\hline$D_{41}$ & $\{1,3\}$ \\
\hline$D_{42}$ & $\{1,2,3,4\}$ \\
\hline$D_{43}$ & $\{3\}$ \\
\hline$D_{45}$ & $\{1\}$ \\
\hline$D_{51}$ & $\{2,3,4\}$ \\
\hline$D_{52}$ & $\{2,3,4,5\}$ \\
\hline$D_{53}$ & $\{2,3,4\}$ \\
\hline$D_{54}$ & $\{2,4\}$ \\
\hline
\end{tabular}

Setelah menentukan concordance dan discordance seperti yang ditunjukkan tabel 8 dan 9, kemudian hitung matriks concordance dan discordance menggunakan persamaan (5) dan (6):

$$
\begin{aligned}
C_{12} & =\mathrm{W}_{3} \\
& =5 \\
\mathrm{C}_{13} & =\mathrm{W}_{1}+\mathrm{W}_{2}+\mathrm{W}_{4}+\mathrm{W}_{5} \\
& =3+5+4+3 \\
& =15 \\
\mathrm{C}_{14} & =\mathrm{W}_{1}+\mathrm{W}_{3}+\mathrm{W}_{4}+\mathrm{W}_{5} \\
& =3+5+4+3 \\
& =15 \\
\mathrm{C}_{15} & =\mathrm{W}_{2}+\mathrm{W}_{5} \\
& =5+3 \\
& =8 \\
\mathrm{C}_{21} & =\mathrm{W}_{1}+\mathrm{W}_{2}+\mathrm{W}_{3}+\mathrm{W}_{4}+\mathrm{W}_{5} \\
& =3+5+5+4+3 \\
& =20 \\
\mathrm{C}_{23} & =\mathrm{W}_{1}+\mathrm{W}_{2}+\mathrm{W}_{4}+\mathrm{W}_{5} \\
& =3+5+4+3 \\
& =15 \\
\mathrm{C}_{24} & =\mathrm{W}_{1}+\mathrm{W}_{2}+\mathrm{W}_{3}+\mathrm{W}_{4}+\mathrm{W}_{5} \\
& =3+5+5+4+3 \\
& =20 \\
\mathrm{C}_{25} & =\mathrm{W}_{2}+\mathrm{W}_{3}+\mathrm{W}_{4}+\mathrm{W}_{5} \\
& =5+5+4+3 \\
& =17 \\
\mathrm{C}_{31} & =\mathrm{W}_{2}+\mathrm{W}_{3}+\mathrm{W}_{5} \\
& =5+5+3 \\
& =13 \\
&
\end{aligned}
$$$$
\mathrm{C}_{32}=\mathrm{W}_{1}+\mathrm{W}_{2}+\mathrm{W}_{3}+\mathrm{W}_{4}
$$$$
=3+5+5+4
$$$$
=17
$$$$
\mathrm{C}_{34}=\mathrm{W}_{1}+\mathrm{W}_{3}+\mathrm{W}_{5}
$$$$
=3+5+3
$$$$
=11
$$$$
\mathrm{C}_{35}=\mathrm{W}_{2}+\mathrm{W}_{3}+\mathrm{W}_{4}+\mathrm{W}_{5}
$$$$
=5+5+4+3
$$$$
=17
$$$$
\mathrm{C}_{41}=\mathrm{W}_{2}+\mathrm{W}_{4}+\mathrm{W}_{5}
$$$$
=5+4+3
$$$$
=12
$$$$
\mathrm{C}_{42}=\mathrm{W}_{4}
$$$$
=4
$$$$
\mathrm{C}_{43}=\mathrm{W}_{1}+\mathrm{W}_{2}+\mathrm{W}_{4}+\mathrm{W}_{5}
$$$$
=3+5+4+3
$$$$
=15
$$$$
\mathrm{C}_{45}=\mathrm{W}_{2}+\mathrm{W}_{3}+\mathrm{W}_{4}+\mathrm{W}_{5}
$$$$
=5+5+4+3
$$$$
=17
$$$$
\mathrm{C}_{51}=\mathrm{W}_{1}+\mathrm{W}_{5}
$$$$
=3+3
$$$$
=6
$$$$
=\mathrm{W}_{1}
$$$$
=3
$$$$
=3
$$ 


$$
\begin{aligned}
\mathrm{C}_{53} & =\mathrm{W}_{1}+\mathrm{W}_{5} & \mathrm{C}_{54} & =\mathrm{W}_{1}+\mathrm{W}_{3}+\mathrm{W}_{5} \\
& =3+3 & & =3+5+3 \\
& =6 & & =11
\end{aligned}
$$

Nilai dari komponen matriks disusun berdasarkan himpunan concordance dengan bobot (W) dan dijumlahkan, sehingga menghasilkan matriks concordance sebagai berikut :

$$
\mathrm{C}=\left[\begin{array}{ccccc}
- & 5 & 15 & 15 & 8 \\
20 & - & 15 & 20 & 17 \\
13 & 17 & - & 11 & 17 \\
12 & 4 & 15 & - & 17 \\
6 & 3 & 6 & 11 & -
\end{array}\right]
$$

Lakukan menghitung discordance dengan menggunakan persamaan (6):

$$
\begin{aligned}
& \operatorname{Max}\{|1,2481-1,6641| ;|1,8898-3,1497| ; \\
& D_{12}=\frac{|2-2| ;|1,2720-1,5900|\}}{\operatorname{Max}\{|1,2481-1,6641| ;|1,8898-3,1497| ;} \\
& |2,3094-2,3094| ;|2-2| ;|1,2720-1,5900|\} \\
& =\frac{\operatorname{Max}\{|0,41603| ;|1,25988| ;|0| ;|0,31800|\}}{\operatorname{Max}\{|0,41603| ;|1,25988| ;|0| ;|0| ;|0,31800|\}} \\
& =\frac{1,25988}{1,25988}=1 \\
& D_{13}= \\
& \frac{\operatorname{Max}\{|2,3094-2,8868|\}}{\operatorname{Max}\{|1,2481-0,4160| ;|1,8898-1,8898| ;} \\
& |2,3094-2,8868| ;|2-1,6| ;|1,2720-1,2720|\} \\
& =\frac{\operatorname{Max}\{|0,57735|\}}{\operatorname{Max}\{|0,83205| ;|0| ;|0,57735| ;|0,4| ;|0|\}} \\
& =\frac{0,57735}{0,83205}=0,6939 \\
& D_{14}=\frac{\operatorname{Max}\{|1,8898-2,5198|\}}{\operatorname{Max}\{|1,2481-0,4160| ;|1,8898-2,5198| ;} \\
& |2,3094-1,7321| ;|2-2| ;|1,2720-1,2720|\} \\
& =\frac{\operatorname{Max}\{|0,62994|\}}{\operatorname{Max}\{|0,83205| ;|0,62994| ;|0,57735| ;|0| ;|0|\}} \\
& =\frac{0,62994}{0,83205}=0,7571 \\
& D_{15}= \\
& \text { Max }\{|1,2481-2,0801| ;|2,3094-1,7321| ;|2-1,2|\} \\
& \text { Max }\{|1,2481-2,0801| ;|1,8898-1,2599| ; \\
& |2,3094-1,7321| ;|2-1,2| ;|1,2720-1,2720|\} \\
& =\frac{\operatorname{Max}\{|0,83205| ;|0,57735| ;|0,8|\}}{\operatorname{Max}\{|0,83205| ;|0,62994| ;|0,57735| ;|0| ;|0|\}} \\
& =\frac{0,83205}{0,83205}=1 \\
& D_{21}= \\
& \frac{\operatorname{Max}\{|0|\}}{\operatorname{Max}\{|1,6641-1,2481| ;|3,1497-1,8898| ;} \\
& |2,3094-2,3094| ;|2-2| ;|1,5900-1,2720|\} \\
& =\frac{\operatorname{Max}\{|0|\}}{\operatorname{Max}\{|0,41603| ;|1,25988| ;|0| ;|0| ;|0,31800|\}} \\
& =\frac{0}{1,25988}=0
\end{aligned}
$$

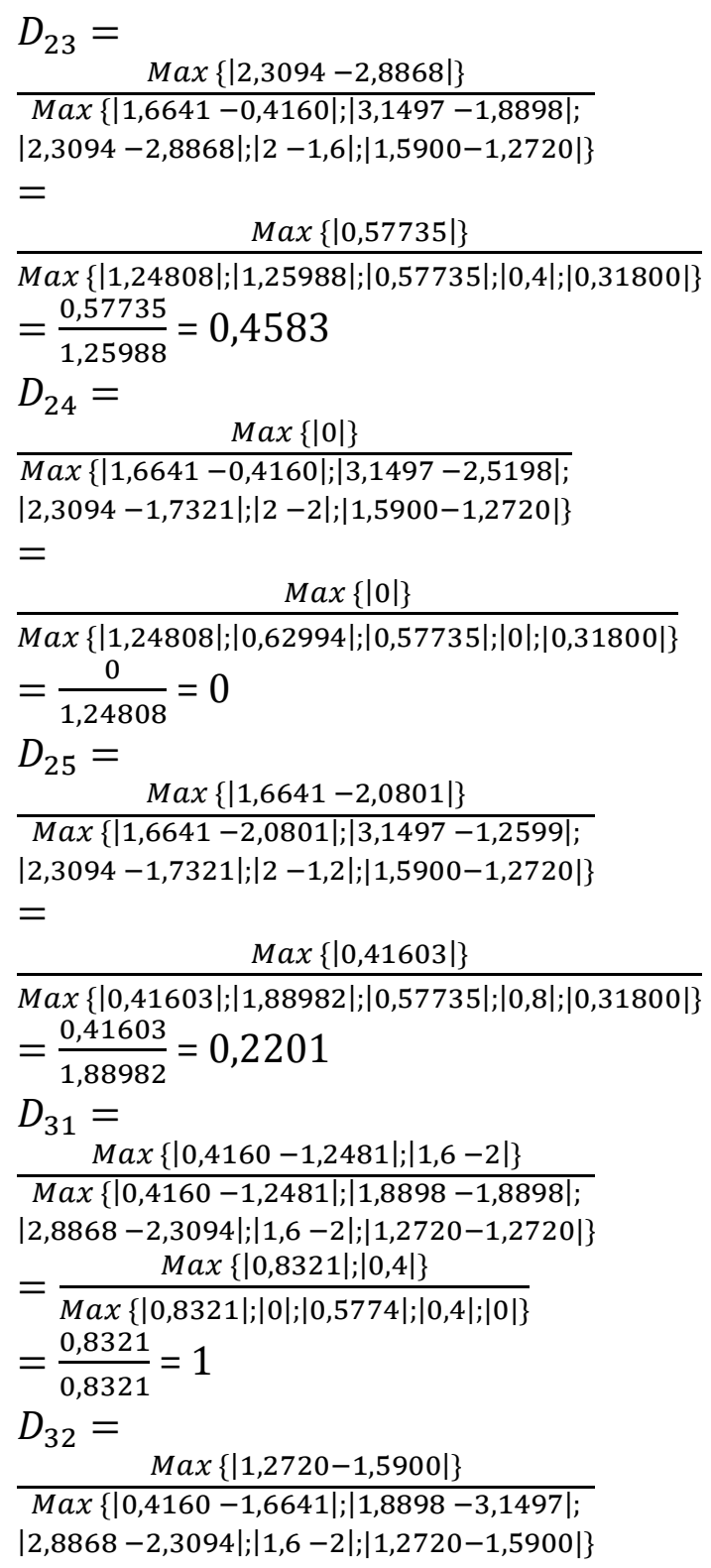




$$
\begin{aligned}
& =\frac{\operatorname{Max}\{|0,3180|\}}{\operatorname{Max}\{|1,2481| ;|1,2599| ;|0,5774| ;|0,4| ;|0,3180|\}} \\
& =\frac{0,3180}{1,2599}=0,2524 \\
& D_{34}= \\
& \operatorname{Max}\{|1,8898-2,5198| ;|1,6-2|\} \\
& \operatorname{Max}\{|0,4160-0,4160| ;|1,8898-2,5198| ; \\
& |2,8868-1,7321| ;|1,6-2| ;|1,2720-1,2720|\} \\
& =\frac{\operatorname{Max}\{|0| ;|0,6299|\}}{\operatorname{Max}\{|0| ;|0,6299| ;|1,1547| ;|0,4| ;|0|\}} \\
& =\frac{0,6299}{1,1547}=0,5455 \\
& D_{35}= \\
& \operatorname{Max}\{|0,4160-2,0801|\} \\
& \operatorname{Max}\{|0,4160-2,0801| ;|1,8898-1,2599| ; \\
& |2,8868-1,7321| ;|1,6-1,2| ;|1,2720-1,2720|\} \\
& =\frac{\operatorname{Max}\{|1,6641|\}}{\operatorname{Max}\{|1,6641| ;|0,6299| ;|1,1547| ;|0,4| ;|0|\}} \\
& =\frac{1,6641}{1,6641}=1 \\
& D_{41}=\frac{\operatorname{Max}\{|0,4160-1,2481| ;|1,7321-2,3094|\}}{\operatorname{Max}\{|0,4160-1,2481| ;|2,5198-1,8898| ;} \\
& |1,7321-2,3094| ;|2-2| ;|1,2720-1,2720|\} \\
& =\frac{\operatorname{Max}\{|0,8321| ;|0,5774|\}}{\operatorname{Max}\{|0,8321| ;|0,6299| ;|0,5774| ;|0| ;|0|\}} \\
& =\frac{0,8321}{0,8321}=1 \\
& \operatorname{Max}\{|0,4160-1,6641| ;|2,5198-3,1497| ; \\
& D_{42}=\frac{|1,7321-2,3094| ;|2-2|\}}{\operatorname{Max}\{|0,4160-1,6641| ;|2,5198-3,1497| ;} \\
& |1,7321-2,3094| ;|2-2| ;|1,2720-1,5900|\} \\
& =\frac{\operatorname{Max}\{|1,2481| ;|0,6299| ;|0,5774| ;|0|\}}{\operatorname{Max}\{|1,2481| ;|0,6299| ;|0,5774| ;|0| ;|0,3180|\}} \\
& =\frac{1,2481}{1,2481}=1 \\
& D_{43}= \\
& \operatorname{Max}\{|1,7321-2,8868|\} \\
& \operatorname{Max}\{|0,4160-0,4160| ;|2,5198-1,8898| ; \\
& |1,7321-2,8868| ;|2-1,6| ;|1,2720-1,2720|\} \\
& =\frac{\operatorname{Max}\{|1,1547|\}}{\operatorname{Max}\{|0| ;|0,6299| ;|1,1547| ;|0,4| ;|0|\}} \\
& =\frac{1,1547}{1,1547}=1
\end{aligned}
$$

$$
\begin{aligned}
& D_{45}= \\
& \frac{\operatorname{Max}\{|0,4160-2,0801|\}}{\operatorname{Max}\{|0,4160-2,0801| ;|2,5198-1,2599| ;} \\
& |1,7321-1,7321| ;|2-1,2| ;|1,2720-1,2720|\} \\
& =\frac{\operatorname{Max}\{|1,6641|\}}{\operatorname{Max}\{|1,6641| ;|1,2599| ;|0| ;|0,8| ;|0|\}} \\
& =\frac{1,6641}{1,6641}=1 \\
& D_{51}= \\
& \operatorname{Max}\{|1,2599-1,8898| ;|1,7321-2,3094| ;|1,2-2|\} \\
& \operatorname{Max}\{|2,0801-1,2481| ;|1,2599-1,8898| ; \\
& |1,7321-2,3094| ;|1,2-2| ;|1,2720-1,2720|\} \\
& =\frac{\operatorname{Max}\{|0,6299| ;|0,5774| ;|0,8|\}}{\operatorname{Max}\{|0,8321| ;|0,6299| ;|0,5774| ;|0,8| ;|0|\}} \\
& =\frac{0,8}{0,8321}=0,9615 \\
& D_{52}= \\
& \operatorname{Max}\{|1,2599-3,1497| ;|1,7321-2,3094| ; \\
& |1,2-2| ;|1,2720-1,5900|\} \\
& \text { Max }\{|2,0801-1,6641| ;|1,2599-3,1497| ; \\
& |1,7321-2,3094| ;|1,2-2| ;|1,2720-1,5900|\} \\
& =\frac{\operatorname{Max}\{|1,8898| ;|0,5774| ;|0,8| ;|0,3180|\}}{\operatorname{Max}\{|0,4160| ;|1,8898| ;|0,5774| ;|0,8| ;|0,3180|\}} \\
& =\frac{1,8898}{1,8898}=1 \\
& D_{53}= \\
& \operatorname{Max}\{|1,2599-1,8898| ;|1,7321-2,8868| \\
& |1,2-1,6|\} \\
& \operatorname{Max}\{|2,0801-0,4160| ;|1,2599-1,8898| ; \\
& |1,7321-2,8868| ;|1,2-1,6| ;|1,2720-1,2720|\}
\end{aligned}
$$

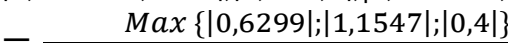

$$
\begin{aligned}
& =\overline{\operatorname{Max}\{|1,6641| ;|0,6299| ;|1,1547| ;|0,4| ;|0|\}} \\
& =\frac{1,1547}{1,6641}=0,6939 \\
& D_{54}= \\
& \operatorname{Max}\{|1,2599-2,5198| ;|1,2-2|\} \\
& \text { Max }\{|2,0801-0,4160| ;|1,2599-2,5198| ; \\
& |1,7321-1,7321| ;|1,2-2| ;|1,2720-1,2720|\} \\
& =\frac{\operatorname{Max}\{|1,2599| ;|0,8|\}}{\operatorname{Max}\{|1,6641| ;|1,2599| ;|0| ;|0,8| ;|0|\}} \\
& =\frac{1,2599}{1,6641}=0,7571
\end{aligned}
$$

sehingga menghasilkan matriks discordance sebagai berikut :

$$
D=\left[\begin{array}{ccccc}
- & 1 & 0,6939 & 0,7571 & 1 \\
0 & - & 0,4583 & 0 & 0,2201 \\
1 & 0,2201 & - & 0,5455 & 1 \\
1 & 1 & 1 & - & 1 \\
0,9615 & 1 & 0,6939 & 0,7571 & -
\end{array}\right]
$$

Setelah itu menentukan threshold dari matriks dominan concordance dan discordance menggunakan persamaan (10) dan (11):

\footnotetext{
$5+15+15+8+20+15+20+17+13+17+$

$\mathrm{C}=\frac{11+7+17+12+4+15+17+6+3+11}{5+(5-1)}$ $5 *(5-1)$
} 
$=\frac{248}{20}$

$=12,35$

Sehingga, matriks dominan concordance adalah :

$\mathrm{F}=\left[\begin{array}{ccccc}- & 0 & 1 & 1 & 0 \\ 1 & - & 1 & 1 & 1 \\ 1 & 1 & - & 0 & 1 \\ 0 & 1 & 1 & - & 1 \\ 0 & 0 & 0 & 0 & -\end{array}\right]$

Menghitung matriks dominan discordance mengunakan Persamaan (11):

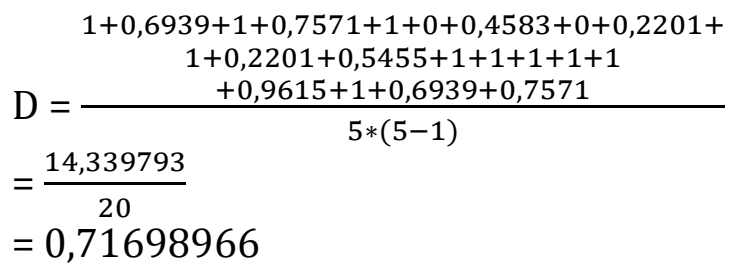

Sehingga, matriks dominan discordance adalah :

$\mathrm{G}=\left[\begin{array}{ccccc}- & 1 & 0 & 1 & 1 \\ 0 & - & 0 & 0 & 0 \\ 1 & 0 & - & 0 & 1 \\ 1 & 1 & 1 & - & 1 \\ 1 & 1 & 0 & 1 & -\end{array}\right]$

Kemudian menentukan aggregate dominance matrix matematis menggunakan Persamaan (12). Matriks $E$ dihasilkan dari perkalian matriks $F$ dan matriks $G$, sebagai berikut :

$\mathrm{F}=\left[\begin{array}{ccccc}- & 0 & 1 & 1 & 0 \\ 1 & - & 1 & 1 & 1 \\ 1 & 1 & - & 0 & 1 \\ 0 & 1 & 1 & - & 1 \\ 0 & 0 & 0 & 0 & -\end{array}\right] \times \mathrm{G}=\left[\begin{array}{ccccc}- & 1 & 0 & 1 & 1 \\ 0 & - & 0 & 0 & 0 \\ 1 & 0 & - & 0 & 1 \\ 1 & 1 & 1 & - & 1 \\ 1 & 1 & 0 & 1 & -\end{array}\right]$

Langkah terakhir adalah mengeliminasi alternatif yang less favourable Matriks $E$ dihasilkan dari perkalian matriks $F$ dan matriks $G$ :

$\mathrm{E}=\left[\begin{array}{ccccc}- & 0 & 0 & 1 & 0 \\ 0 & - & 0 & 0 & 0 \\ 1 & 0 & - & 0 & 1 \\ 0 & 1 & 1 & - & 1 \\ 0 & 0 & 0 & 0 & -\end{array}\right]$

Matriks $E$ memberikan urutan pilihan dari setiap alternatif, yaitu bila $e_{k l}=1$ maka alternative $A_{k}$ merupakan pilihan yang lebih baik daripada $A_{k}$. Sehingga baris dalam matriks $E$ yang memiliki jumlah $e_{k l}=1$ paling sedikit dapat dieliminasi. Hasil dari perhitungan dengan metode ELECTRE pada pemilihan laptop gaming high end yang ideal untuk Gamer Professional adalah Acer Predator Triton 700 (A4). 


\section{SIMPULAN}

Berdasarkan hasil penelitian dapat disimpulkan bahwa metode ELECTRE dapat diterapkan pada pemilihan laptop gaming high end yang ideal untuk Gamer Professional dengan mempertimbangkan lima kriteria yaitu: Harga, Jenis Processor, Kapasitas RAM, Jenis Kartu VGA, Hardisk dan lima alternatif yaitu: Asus ROG G703 (A1), Razer Blade Pro (A2) MSI GT75VRTitan-083 (A3), Acer Predator Triton 700 (A4), Alienware 17(A5).

\section{DAFTAR PUSTAKA}

[1] A. N. Hidayat, N. A. Muhammad, and H. Suryotrisongko, "Integrasi Aplikasi Android dan Komputer Server sebagai Solusi Mobile Commerce dan CRM Studi Kasus Toko Game XYZ," Semin. Nas. Teknol. Inf. Komun. Terap. 2012 (Semantik 2012) Semarang, 23 Juni 2012 ISBN, vol. 2012, no. Semantik, pp. 108-113, 2012.

[2] E. G. Sihombing, E. Arisawati, L. S. Dewi, F. Handayanna, and R. R, "Sistem Pendukung Keputusan Dengan Metode Simple Multi Attribute Rating Technique Pada Pemilihan Toko Roti," InfoTekJar J. Nas. Inform. dan Teknol. Jar., vol. 3, no. 2, pp. 159-163, 2019.

[3] D. R. Sari, A. P. Windarto, and D. Hartama, "Sistem Pendukung Keputusan untuk Rekomendasi Kelulusan Sidang Skripsi Menggunakan Metode AHP-TOPSIS," J. Teknol. dan Sist. Komput., vol. 6, no. November 2017, pp. 1-6, 2018.

[4] C. Irwana, Z. F. Harahap, and A. P. Windarto, "SPK: ANALISA METODE MOORA PADA WARGA PENERIMA BANTUAN RENOVASI RUMAH," JTI, vol. 10, no. 1, pp. 47-54, 2018.

[5] T. Novika, A. Widiastari, V. Miralda, and A. P. Windarto, "SPK: ANALISA REKOMENDASI BANK KONVENSIONAL DENGAN PROMETHEE SEBAGAI SOLUSI CERDAS UNTUK MENABUNG," JUSIM, vol. 3, no. 1, pp. 38-45, 2018.

[6] E. Satria, N. Atina, M. E. Simbolon, and A. P. Windarto, "SPK : ALGORITMA MULTI-ATTRIBUTE UTILITY THEORY ( MAUT ) PADADESTINASI TUJUAN WISATA LOKAL DI KOTA SIDAMANIK," CESS Journal Comput. Eng. Syst. Sci., vol. 3, no. 2, pp. 75-79, 2018.

[7] N. Purba, K. Apni, P. Sari, and A. P. Windarto, "SPK : ANALISIS METODE VIKOR DALAM MEREKOMENDASIKAN," J. Inform., vol. 18, no. 2, pp. 108-115, 2018.

[8] A. P. W. Gumilar Ramadhan Pangaribuan, W. P. Mustika, and A. Wanto, "Pemilihan Jenis Sapi bagi Peternak Sapi Potong dengan Metode SMART," Algoritm. J. Ilmu Komput. dan Inform., vol. 3, no. 1, pp. 30-37, 2019.

[9] D. N. Batubara, D. R. S. P, and A. P. Windarto, "Penerapan Metode PROMETHEE II Pada Pemilihan Situs Travel Berdasarkan Konsumen," J. SISFOKOM, vol. 8, no. 1, pp. 46-52, 2019.

[10] S. Sundari et al., "Sistem Pendukung Keputusan Dengan Menggunakan Metode Electre Dalam Merekomendasikan Dosen Berprestasi Bidang Ilmu Komputer ( Study Kasus di AMIK \& STIKOM Tunas Bangsa )," no. X, pp. 1-6, 2017.

[11] D. M. Sinaga, S. M. Dewi, and A. P. Windarto, "Penerapan Algoritma ELECTRE Pada Pemilihan Produk Skincare," vol. 13, no. 2, 2018.

[12] R. W. Sari, A. P. Windarto, S. P. Keputusan, P. Kreatifitas, M. Pkm, and A. D. A. N. Pembahasan, "Penerapan Electree Pada Seleksi Proposal Program Kreativitas Mahasiswa ( PKM ) di STIKOM Tunas Bangsa," pp. 800-806, 2019.

[13] S. R. Ningsih, I. S. Damanik, I. Gunawan, and W. Saputra, "SISTEM PENDUKUNG KEPUTUSAN DENGAN MENGGUNAKAN METODE ELECTRE DALAM MENENTUKAN PENERIMA PROGRAM INDONESIA PINTAR (PIP) MELALUI KARTU INDONESIA PINTAR (KIP) (STUDI KASUS: SD SWASTA AL - 
WASHLIYAH MOHO KABUPATEN SIMALUNGUN)," KOMIK (Konferensi Nas. Teknol. Inf. dan Komputer), vol. 1, no. 1, Nov. 2017.

[14] S. R. Ningsih, I. S. Damanik, I. Gunawan, and W. Saputra, "ELECTRE DALAM MENENTUKAN PENERIMA PROGRAM INDONESIA PINTAR ( PIP ) MELALUI KARTU INDONESIA PINTAR (KIP) (STUDI KASUS: SD SWASTA AL WASHLIYAH MOHO KABUPATEN SIMALUNGUN )," vol. I, pp. 264-275, 2017.

[15] S. R. Ningsih and A. P. Windarto, "Penerapan Metode Promethee II Pada Dosen Penerima Hibah P2M Internal," InfoTekJar Uurnal Nas. Inform. dan Teknol. Jaringan), vol. 3, no. 1, pp. 20-25, 2018.

[16] M. Mesran, G. Ginting, S. Suginam, and R. Rahim, "Implementation of Elimination and Choice Expressing Reality (ELECTRE) Method in Selecting the Best Lecturer (Case Study STMIK BUDI DARMA)," Int. J. Eng. Res. Technol., vol. 6, no. 2, NaN-2017, pp. 141-144, 2017.

[17] Ermatita, Sri Hartati, R. Wardoyo, and A. Harjoko, "Electre Methods in Solving Group Decision Support System Bioinformatics on Gene Mutation Detection Simulation," Int. J. Comput. Sci. Inf. Technol., vol. 3, no. 1, pp. 40-52, 2011.

[18] W.-C. C. Huang and C.-H. H. Chen, "Using the ELECTRE II method to apply and analyze the differentiation theory," Proc. East. Asia Soc. Transp. Stud., vol. 5, no. January 2005, pp. 2237-2249, 2005. 